\title{
Determination of Ballistic Limit for IM7/8552 Using Peridynamics
}

\author{
Fernando Cuenca $^{1}$ and Olaf Weckner ${ }^{2}$ \\ Boeing Commercial Airplanes, Everett, WA, 98204, USA \\ Stewart A. Silling ${ }^{3}$ \\ Sandia National Laboratories, Albuquerque, NM, 87185, USA \\ and \\ Jenna Pang ${ }^{4}$, Mostafa Rassaian ${ }^{5}$ \\ Boeing Research And Technology, Seattle, WA,98108
}

\begin{abstract}
Significant testing is required to design and certify primary aircraft structure subject to High Energy Dynamic Impact (HEDI) events; current work under the NASA Advanced Composites Consortium (ACC) HEDI Project seeks to determine the state-of-the-art of dynamic fracture simulations for composite structures in these events. This paper discusses one of four Progressive Damage Analysis (PDA) methods selected for this project: peridynamics, through EMU implementation. A brief discussion of peridynamic theory is provided, followed by an outline of ballistic impact testing performed for model development and assessment. Detailed modeling approach and test-analysis correlation for a single open test case are presented, followed by the results of a series of blind predictions made prior to testing and test-analysis correlation performed with measured NASA test results. Specifically, we present simulation results for the ballistic limit $\left(V_{50}\right)$ of IM7/8552 composite panels ballistically tested with an impactor representative of a high-velocity fan-blade-out condition. In particular, force and displacement history and the damage state determined analytically are compared to measured results. Ultimately, peridynamics has the ability to predict damage patterns, impact force and deflections during a high energy dynamic impact event on composite panels of different layups using two different types of impactors. Blind predictions were promising and increased confidence in the model for impact simulation. There are open questions regarding the fidelity of the test fixture idealization in regards to stiffness and damping which will need to be addressed in future work.
\end{abstract}

\section{Introduction}

The goal of the NASA Advanced Composites Consortium (ACC) High Energy Dynamic Impact (HEDI) Project is to determine the state of the art of dynamic fracture simulations for high velocity impact for composite fuselage shielding applications. Using a building block approach, the computational models considered under NASA ACC are being validated against test data, starting at unconfigured panels all the way to configured panels with bolted and

\footnotetext{
${ }^{1}$ Structural Analysis Engineer, Structural Methods And Allowables, 3003 West Casino Road, Everett WA 98204, MC: 03-JP, Member.

2 Structural Analysis Engineer, 777x Wing, 3003 West Casino Road, Everett WA 98204, MC: 03-28, AIAA Senior Member.

${ }^{3}$ Distinguished Member of the Technical Staff, Center for Computing Research, MS-1322, P.O. Box 5800, Sandia National Laboratories, Albuquerque, NM 87185-1322 USA, AIAA Fellow.

${ }^{4}$ Structural Analysis Engineer, Structures Technology, 9725 East Marginal Way South, Tukwila, WA 98108, MC: 42-56, Non-Member.

5 Technical Fellow, Structures Technology, 9725 East Marginal Way South, Tukwila, WA 98108, MC: 42-56, AIAA Associate Fellow.
}

American Institute of Aeronautics and Astronautics 
bonded stiffeners. Several progressive failure analysis methods were downselected by the consortium, including particle methods such as SPG (LS-DYNA), element based based methods such as MAT162, MAT261 and MAT213 (LS-DYNA) as well as integral methods such as peridynamics (EMU tool developed by Sandia National Laboratories). An overview of the various methods is provided in References $1-4$. This paper describes the peridynamic analysis approach and test-analysis correlation.

The Peridynamics (PD) theory and the allied code EMU can be used to model damage propagation in composite materials. The term peridynamic, an adjective, comes from the prefix peri, which means all around, near, or surrounding; and the root dyna, which means force or power. The term peridynamics, a noun, is a shortened form of the phrase "peridynamic model of solid mechanics". The EMU code is used to solve the peridynamic equations numerically. The so-called bond-based peridynamic theory was first introduced in 2000 in Reference 5. Due to shortcomings in the material behavior captured the theory was extended in 2007 to what is known as the state-based peridynamic formulation, see Reference 6. Both state-based and bond-based theories used the Lagrangian description of the material points. In 2017 the theory was further extended to include a Eulerian description needed in the context of large deformations such as bird strike onto aircraft structures, see Reference 7.

The following is a short and general introduction to the non-local peridynamic theory and how it differs from the traditional, local FE methods. The equation of motion in the classical theory of continuum mechanics is:

$$
\rho(\mathbf{x}) \ddot{\mathbf{u}}(\mathbf{x}, t)=\nabla \bullet \boldsymbol{\sigma}(\mathbf{x}, t)+\mathbf{b}(\mathbf{x}, t)
$$

Here $\boldsymbol{\rho}$ is the density, $\mathbf{u}$ is the displacement field, $\boldsymbol{\sigma}$ is the stress tensor and $\mathbf{b}$ represents the external force density field. Furthermore, $\mathrm{t}$ is the time and $\mathbf{x}$ is the position in the reference configuration. By definition, the spatial derivatives appearing in the divergence operator representing the resulting interior force do not exist for discontinuous fields. Therefore, whenever discontinuities such as cracks appear, the formulation (1) breaks down. Special techniques have been developed in the theory of fracture mechanics to work around this problem, but these techniques typically have to overcome the following two (major) difficulties:

1. In the presence of multiple cracks growing in directions not known in advance these methods require an increasing amount of numerical book keeping to keep track of the crack front and therefore become computationally cumbersome.

2. Another difficulty is that supplemental relations for crack initiation and crack propagation are needed to obtain a closed set of equations of (1). The choice of these (often semi-empirical) relations influences the solution of (1) and it is not obvious which choice results in the best solution compared to experiments for composite materials. Examples are element erosion criteria (in-plane damage) or the parameters governing the tiebreak contact between plies (delaminations) used in tranditional FEM models. These difficulties are inherited by numerical methods that implement the classical theory such as finite element and finite difference methods. These two difficulties do not arise in PD modeling as will be shown below.

The PD theory reforms the basic equation of motion in the form of equation (2) so that they can be applied regardless of whether a discontinuity occurs. The interior forces are modeled using an integral operator rather than a differential operator. Physically this can be interpreted as the natural extension of molecular dynamics to continuum mechanics. As an integral operator can handle jump discontinuities commonly appearing in fracture mechanics, its applicability exceeds that of the classical formulation (1). Because the same equations apply both points of smooth deformation as well as in singular regions there is no need for an externally supplied crack initiation and crack growth law. The equation of motion in the bond-based PD theory is

$$
\rho \ddot{\mathbf{y}}(\mathbf{x}, t)=\int_{\mathcal{H}} \mathbf{f}\left(\mathbf{x}^{\prime}, \mathbf{x}, t\right) d V_{\mathbf{x}^{\prime}}+\mathbf{b}(\mathbf{x}, t)
$$

The variable $\mathbf{f}$ is the pairwise force function whose value is the force vector (per unit reference volume squared) that the particle $\mathbf{x}^{\prime}$ exerts on the particle $\mathbf{x}$. The physical interaction between $\mathbf{x}^{\prime}$ and $\mathbf{x}$ is referred to as a bond. It is 
computationally convenient (as well as physically justified) to assume that material particles separated in the reference configuration by a distance greater than some fixed distance, $\boldsymbol{\delta}$, do not interact. This distance is called the horizon of the material. Figure 1 illustrates the variables used.

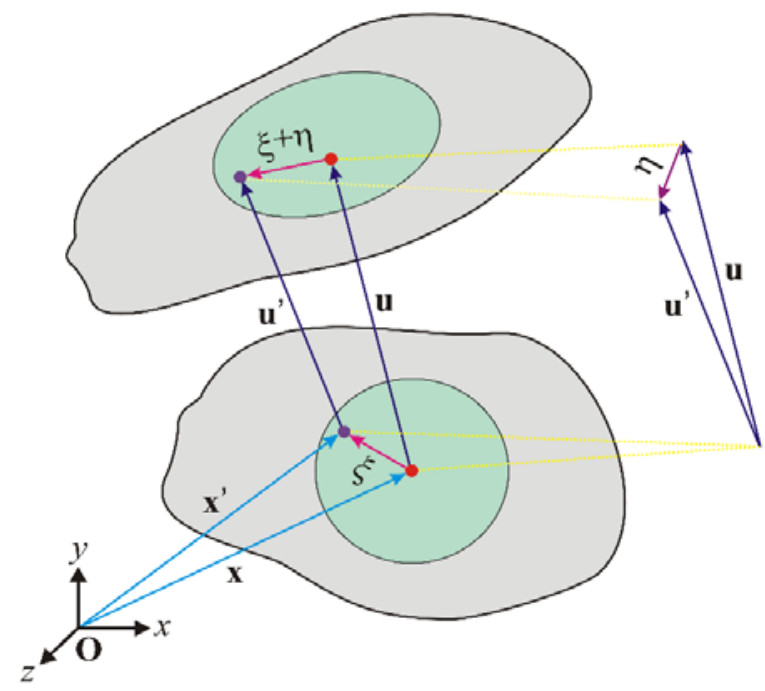

Figure 1. Kinematics and PD Horizon

Failure occurs whenever a bond exceeds its critical bond strain, see Figure 2. The stiffness and critical strain is different for bonds aligned with the fiber direction in a given ply, as opposed to all other so-called matrix bonds, see Figure 2. Section II describes the details of the failure mechanism in peridynamics and Table 4 shows all input parameters used in the peridynamic simulation presented, together with the test method needed to obtain them.

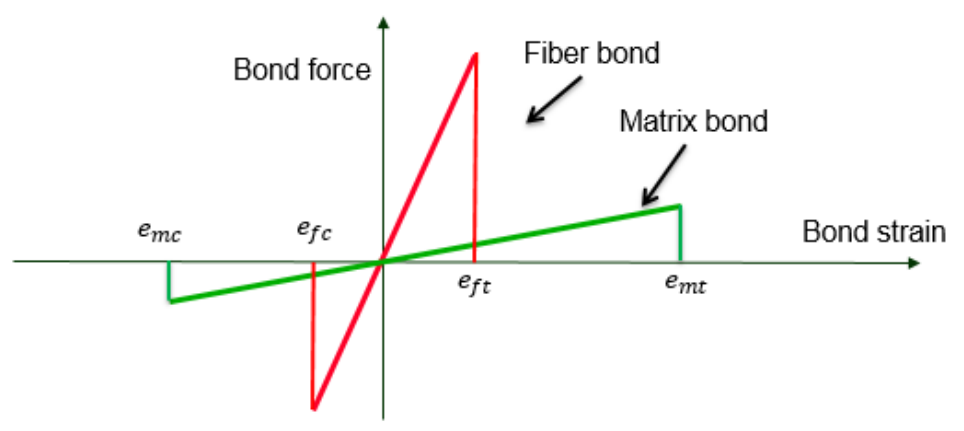

Figure 2. Constitutive model for composites in peridynamics

This paper is organized as follows. Simulation inputs and parameters used for $\mathrm{V}_{50}$ predictions of flat panel impact testing are discussed in Section II. Additionally a detailed test-analysis correlation for panel deflection and impact force history is shown for one test case. In Section III, we present a series of blind predictions for multiple blunt and sharp impactors, which were performed to determine the ballistic limit. Note that the blind predictions were performed prior to the test analysis correlation shown in Section II.

American Institute of Aeronautics and Astronautics 


\section{Test Description, Peridynamic Simulation Setup and Test-Analysis Correlation for Open Test Case T-B-06}

\section{A. Description of the Test Articles and Test Matrix}

The ballistic limit test articles were grouped into three sets: unidirectional (UD) tape panels in two forms of traditional and non-traditional laminates, fabric-only panels, and hybrid UD tape/fabric. Between these sets of panels, there were a total of five different panel types including two types of tape panels and two types of hybrid panels. Schematics for each of the panel types are shown in Figure 3. The UD tape has a nominal ply thickness of 0.0072”. The fabric is a plain weave microstructure with a nominal thickness of 0.0078 ”.

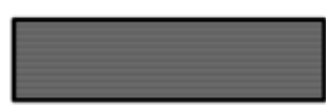

UD Tape Panel - TL

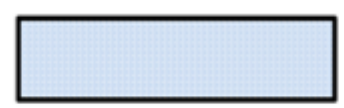

Fabric Panel

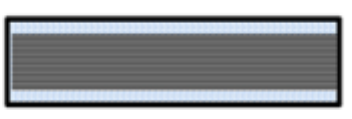

Hybrid2

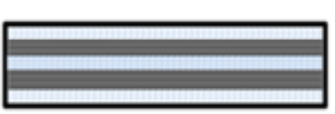

Hybrid3

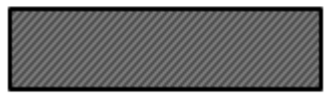

UD Tape Panel - NTL

Figure 3. Schematic of the impact test panel configurations.

Each of the panels were sized to 25" x 25" and extracted from the bulk panel with waterjet cutting. The hybrid tape/fabric coupons were made primarily using UD tape; however, two different hybrid configurations were examined. One configuration consisted of two fabric plies on each side of impact test panel with UD tape in-between. The other configuration consisted of three fabric layers with the additional fabric layer located at the center of the layup stack.

The test matrices for each of these test articles are shown in Table 1, Table 2, and Table 3. Test configurations consider 40- and 56-ply panels with both traditional (TL) and non-traditional laminates (NTL). NTLs are defined as layups with ply angles that do not fall into the traditional $0 \% 145^{\circ} / 45^{\circ} / 90^{\circ}$ design space. 
Table 1. Test Matrix for the IM7/8552 UD Tape Panel Impact Specimens

\begin{tabular}{|c|c|c|c|c|c|c|c|}
\hline \multirow{2}{*}{ Test ID } & \multicolumn{3}{|c|}{ Flat Panel } & \multicolumn{4}{c|}{ Projectile } \\
\cline { 2 - 8 } & $\begin{array}{c}\text { Material } \\
\text { Form }\end{array}$ & $\begin{array}{c}\text { Thickness } \\
\text { (in.) }\end{array}$ & Layup & Shape & $\begin{array}{c}\text { Weight } \\
\text { (Ibs) }\end{array}$ & $\begin{array}{c}\text { Velocity } \\
\text { (ft/s) }\end{array}$ & Orientation \\
\hline \hline T-B-01 & Tape & 0.288 & TL (40p) & Blunt & 0.93 & 587 & Axial \\
\hline T-B-02 & Tape & 0.288 & TL (40p) & Blunt & 0.93 & 667 & Axial \\
\hline T-B-03 & Tape & 0.288 & TL (40p) & Sharp & 0.75 & 290 & Axial \\
\hline T-B-04 & Tape & 0.288 & TL (40p) & Blunt & 0.93 & 628 & Axial \\
\hline T-B-05 & Tape & 0.288 & TL (40p) & Sharp & 0.75 & 362 & Axial \\
\hline T-B-06 & Tape & 0.288 & TL (40p) & Sharp & 0.75 & 218 & Axial \\
\hline T-B-07 & Tape & 0.4032 & TL (56p) & Blunt & 0.93 & 670 & Axial \\
\hline T-B-08 & Tape & 0.4032 & TL (56p) & Blunt & 0.93 & 730 & Axial \\
\hline T-B-09 & Tape & 0.4032 & TL (56p) & Blunt & 0.93 & 806 & Axial \\
\hline T-B-10 & Tape & 0.4032 & TL (56p) & Sharp & 0.75 & 362 & Axial \\
\hline T-B-11 & Tape & 0.288 & NTL (40p) & Blunt & 0.93 & 589 & Axial \\
\hline T-B-12 & Tape & 0.288 & NTL (40p) & Blunt & 0.93 & 628 & Axial \\
\hline T-B-13 & Tape & 0.4032 & NTL (56p) & Sharp & 0.75 & 284 & Axial \\
\hline T-B-14 & Tape & 0.4032 & NTL (56p) & Sharp & 0.75 & 363 & Axial \\
\hline T-S-01 & Tape & 0.288 & TL (40p) & Blunt & 0.93 & 716 & Axial \\
\hline T-S-02 & Tape & 0.288 & TL (40p) & Sharp & 0.75 & 239 & Axial \\
\hline T-S-03 & Tape & 0.4032 & TL (56p) & Sharp & 0.75 & 289 & Axial \\
\hline T-S-04 & Tape & 0.4032 & TL (56p) & Sharp & 0.75 & 355 & Axial \\
\hline T-S-05 & Tape & 0.288 & NTL (40p) & Sharp & 0.75 & 227 & Axial \\
\hline T-S-06 & Tape & 0.288 & NTL (40p) & Sharp & 0.75 & 264 & Axial \\
\hline T-S-07 & Tape & 0.288 & NTL (40p) & Blunt & 0.93 & 660 & Axial \\
\hline
\end{tabular}

Table 2: Test Matrix for the IM7/8552 Fabric Panel Impact Specimens

\begin{tabular}{|c|c|c|c|c|c|c|c|}
\hline \multirow{2}{*}{ Test ID } & \multicolumn{3}{|c|}{ Flat Panel } & \multicolumn{4}{c|}{ Projectile } \\
\cline { 2 - 8 } & $\begin{array}{c}\text { Material } \\
\text { Form }\end{array}$ & $\begin{array}{c}\text { Thickness } \\
\text { (in.) }\end{array}$ & Layup & Shape & $\begin{array}{c}\text { Weight } \\
\text { (lbs) }\end{array}$ & $\begin{array}{c}\text { Velocity } \\
\text { (ft/s) }\end{array}$ & Orientation \\
\hline \hline F-B-01 & Fabric & 0.312 & Fabric (40p) & Blunt & 0.93 & 663 & Axial \\
\hline F-B-02 & Fabric & 0.312 & Fabric (40p) & Blunt & 0.93 & 592 & Axial \\
\hline F-B-03 & Fabric & 0.312 & Fabric (40p) & Blunt & 0.93 & 461 & Axial \\
\hline F-S-01 & Fabric & 0.312 & Fabric (40p) & Sharp & 0.75 & 292 & Axial \\
\hline F-S-02 & Fabric & 0.312 & Fabric (40p) & Sharp & 0.75 & 234 & Axial \\
\hline F-S-03 & Fabric & 0.312 & Fabric (40p) & Sharp & 0.75 & 260 & Axial \\
\hline
\end{tabular}


Table 3: Test Matrix for IM7/8552 Hybrid Panel Impact Specimens

\begin{tabular}{|c|c|c|c|c|c|c|c|}
\hline \multirow[b]{2}{*}{ Test ID } & \multicolumn{3}{|c|}{ Flat Panel } & \multicolumn{4}{|c|}{ Projectile } \\
\hline & $\begin{array}{c}\text { Material } \\
\text { Form }\end{array}$ & $\begin{array}{c}\text { Thickness } \\
\text { (in.) }\end{array}$ & Layup & Shape & $\begin{array}{l}\text { Weight } \\
\text { (lbs) }\end{array}$ & $\begin{array}{c}\text { Velocity } \\
(\mathrm{ft} / \mathrm{s})\end{array}$ & Orientation \\
\hline H2-B-01 & Hybrid & 0.3036 & TL (40p) w/ 2 fabric plies & Blunt & 0.93 & 668 & Axial \\
\hline $\mathrm{H} 2-\mathrm{B}-02$ & Hybrid & 0.3036 & TL (40p) w/ 2 fabric plies & Blunt & 0.93 & 711 & Axial \\
\hline $\mathrm{H} 2-\mathrm{B}-03$ & Hybrid & 0.3036 & TL (40p) w/ 2 fabric plies & Blunt & 0.93 & 663 & Axial \\
\hline H2-S-01 & Hybrid & 0.3036 & TL (40p) w/ 2 fabric plies & Sharp & 0.75 & 293 & Axial \\
\hline $\mathrm{H} 2-\mathrm{S}-02$ & Hybrid & 0.3036 & TL (40p) w/ 2 fabric plies & Sharp & 0.75 & 228 & Axial \\
\hline $\mathrm{H} 2-\mathrm{S}-03$ & Hybrid & 0.3036 & TL (40p) w/ 2 fabric plies & Sharp & 0.75 & 263 & Axial \\
\hline H3-B-01 & Hybrid & 0.3114 & TL (40p) w/ 3 fabric plies & Blunt & 0.93 & 633 & Axial \\
\hline H3-B-02 & Hybrid & 0.3114 & TL (40p) w/ 3 fabric plies & Blunt & 0.93 & 670 & Axial \\
\hline H3-B-03 & Hybrid & 0.3114 & TL (40p) w/ 3 fabric plies & Blunt & 0.93 & 648 & Axial \\
\hline H3-S-01 & Hybrid & 0.3114 & TL (40p) w/ 3 fabric plies & Sharp & 0.75 & 266 & Axial \\
\hline $\mathrm{H} 3-\mathrm{S}-02$ & Hybrid & 0.3114 & TL (40p) w/ 3 fabric plies & Sharp & 0.75 & 286 & Axial \\
\hline H3-S-03 & Hybrid & 0.3114 & TL (40p) w/ 3 fabric plies & Sharp & 0.75 & 255 & Axial \\
\hline H3-S-04 & Hybrid & 0.4266 & TL (56p) w/ 3 fabric plies & Sharp & 0.75 & 285 & Axial \\
\hline H3-S-05 & Hybrid & 0.4266 & TL (56p) w/ 3 fabric plies & Sharp & 0.75 & 340 & Axial \\
\hline H3-S-06 & Hybrid & 0.4266 & TL (56p) w/ 3 fabric plies & Sharp & 0.75 & 350 & Axial \\
\hline
\end{tabular}

\section{B. Ballistic Impact Test Setup}

Ballistic impact tests were performed at the NASA Glenn Research Center (GRC) and post-test Non-Destructive Evaluation (NDE) and inspection were conducted by Boeing in Seattle, Washington. Many of the tests employed common inspection and analysis techniques. Prior to testing, all panels were individually photographed with a 10+ megapixel camera.

\section{Test Fixture}

The test fixture was provided by NASA Glenn Research Center. The GRC fixture was fabricated by the GRC team as showin in Figure 4. The panel was supported between two square frames and held securely along the edges of the test article. A total of $48 \frac{1}{2}$ " diameter 13 grade 8 bolts extended through the front frame, the specimen and the rear frame and were torqued to $70 \mathrm{ft}$-lb with $1 / 2$ ” 13 grade 8 nuts. The rear fixture frame was connected to the upright supports through four piezoelectric load cells. The load cells isolated the frame from the supports and therefore measured the total force between the two. Figure shows the complete test fixture.

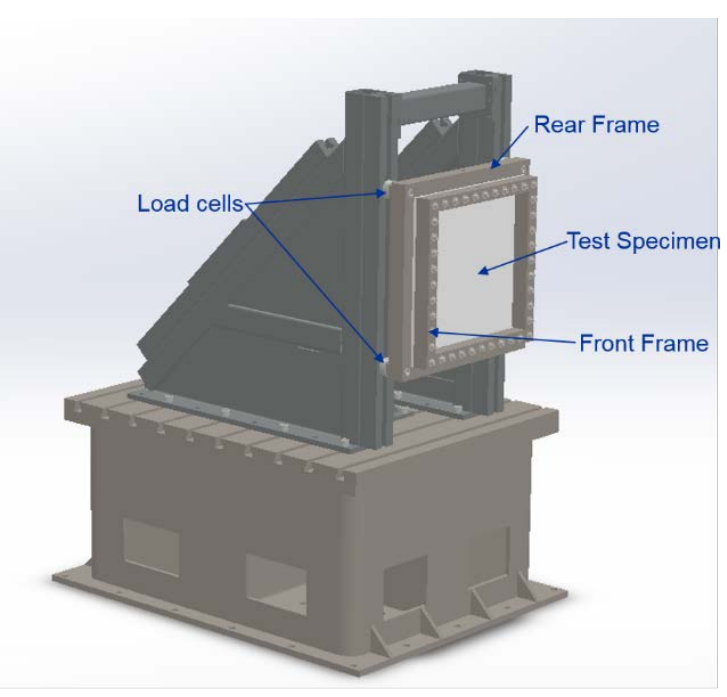

Figure 4. Schematic of the impact test fixture provided by NASA Glenn. 


\section{Projectiles and Gas Gun}

Impact testing consisted of two separate projectiles called "blunt" and "sharp." The blunt projectile consisted of a cylinder with 3" diameter and 3.5" length made of the rubber compound Flexane ${ }^{\circledR} 94$. The sharp projectile was an assembly consisting of a 2" x 2" x 0.25 ” Ti6Al4Vn square insert embedded in Flexane ${ }^{\circledR} 94$ and encased in a hard foam sabot. Figure 5 shows an image of both projectiles. The approximate weight of the blunt and sharp projectiles was $0.95 \mathrm{lbs}$ and $0.75 \mathrm{lbs}$, respectively.
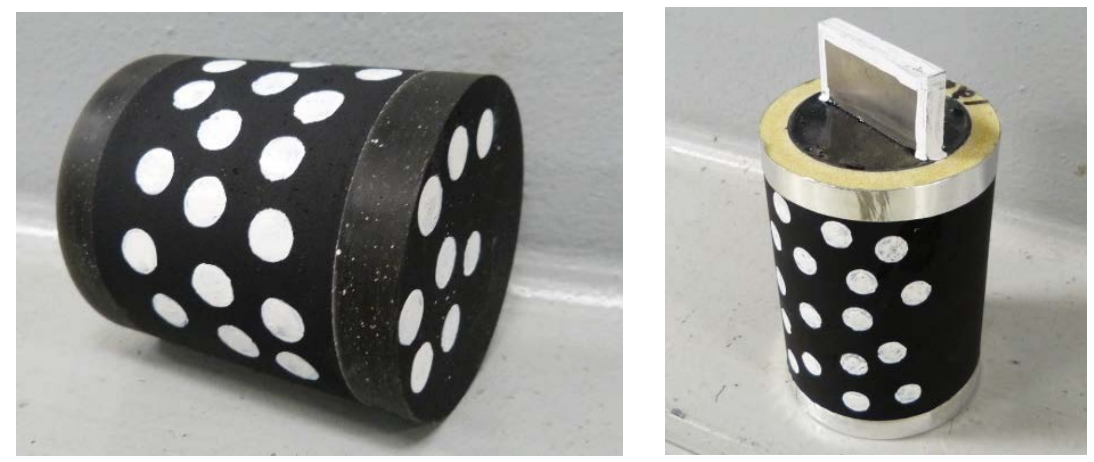

Figure 5: Image of blunt (left) and sharp (right) projectiles with markers for photogrammetric measurements.

The projectile was impacted into the test specimen using a single stage gas gun with an inner diameter of three inches, a length of 23 feet and a pressure vessel volume of 1900 cubic inches. Nitrogen gas was used for the propellant.

\section{Peridynamics Simulation For Open Test Case T-B-06}

A single test case with the test ID T-B-06 was selected as an open test case for the various progressive failure methods considered under NASA ACC, prior to submitting blind $\mathrm{V}_{50}$ predictions for all other tests conducted at NASA. The panel consists of 40 tape plies made of IM7/8552 material system with the following quasi-isotropic stacking: [-45/90/45/0 $]_{5 s}$. Each ply is 0.0072 ” thick, resulting in a panel thickness of 0.288 ”. The sharp impactor was shot at $218 \mathrm{ft} / \mathrm{s}$ and consists of a $0.15 \mathrm{lb}$ titanium blade embedded in a $0.60 \mathrm{lb}$ flexane cylinder.

For the peridynamic simulation we discretize each of the 40 plies of the 25 ” x 25 ” square panel using a uniform inplane grid spacing of 0.142 ", resulting in over 1.25 million nodes for the composite panel. About 400,000 are used to model the picture frame and the load cells. Finally about 9,000 nodes were used to explicitely model thesharp projectile. The total number of nodes in the simulation is about 1.65 million. The peridynamic horizon was chosed to be slightly larger than twice the in-plane grid spacing, $\delta=0.3$ " During the explicit time integration a constant time step of $\mathrm{dt}=2 . \mathrm{e}-7 \mathrm{~s}$ was used.

The composite lamina material model consists of bonds in the fiber and matrix directions. The stiffness of these bonds can be determined as a function of the four in-plane elstic constants E11, E22, G12, v12 by looking at homogeneous deformations of the lamina. Damage is propagated when these bonds exceed their critical bond strain, which is different in tension and compression. These bond strains are chosen to match the failure strains acquired through material testing shown in Table 4. Delaminations are captured through out-of-plane bonds wich are governed by critical shear and normal strains representing mode I and mode II. The flexane and titanium blade are modeled as linearly elastic isotropic materials and it is assumed they do not undergo any damage propagation. All material model inputs and their test conditions are listed in Table 4. 
Table 4 Peridynamic material model input parameters for IM7/8552

\begin{tabular}{|c|c|c|c|}
\hline Parameter & Description & Test Conditions & Parameters \\
\hline$\rho$ & Density & Scale & $98.6 \mathrm{lb} / \mathrm{ft}^{3}$ \\
\hline$E_{11}$ & Lamina elastic modulus & Uniaxial tension & $22.05 \mathrm{Msi}$ \\
\hline$E_{22}$ & Lamina elastic modulus & Uniaxial tension & $1.355 \mathrm{Msi}$ \\
\hline$v_{12}$ & Lamina Poisson ratio & Uniaxial tension & 0.356 \\
\hline$G_{12}$ & Lamina shear modulus & Shear & $0.68 \mathrm{Msi}$ \\
\hline$E_{33}$ & Transverse elastic modulus & Compression thru thickness & $1.355 \mathrm{Msi}$ \\
\hline$G_{13}$ & Transverse shear modulus & Shear thru thickness & $0.68 \mathrm{Msi}$ \\
\hline$e_{f c 0}$ & Fiber failure strain (compression) & Uniaxial compression (0deg) & -0.01229 \\
\hline$e_{f t 0}$ & Fiber failure strain (tension) & Uniaxial tension (0deg) & 0.01578 \\
\hline$e_{m c 0}$ & Matrix failure strain (compression) & Uniaxial compression (90deg) & -0.0294 \\
\hline$e_{m t 0}$ & Matrix failure strain (tension) & Uniaxial tension (90deg) & 0.00715 \\
\hline$e_{m s 0}$ & Matrix failure strain (shear) & Shear (+/- 45deg) & 0.01944 \\
\hline$G_{I C}$ & $\begin{array}{l}\text { Delamination energy release rate } \\
\text { (mode I) }\end{array}$ & Double Cantilever B eam (DCB) & $0.114 \mathrm{in}-\mathrm{lbf} / \mathrm{in}^{2}$ \\
\hline \multirow[t]{5}{*}{$G_{I I c}$} & $\begin{array}{l}\text { Delamination energy release rate } \\
\text { (mode II) }\end{array}$ & End Notch Flexure (ENF) & $0.352 \mathrm{in}-\mathrm{lbf} / \mathrm{in}^{2}$ \\
\hline & Blade bulk modulus & & 14.5 Msi \\
\hline & Flexane bulk modulus & & $0.29 \mathrm{Msi}$ \\
\hline & Ti blade Poisson ratio & & 0.3 \\
\hline & Flexane Poisson ratio & & 0.49167 \\
\hline
\end{tabular}

An overview of the peridynamic grid is shown in Figure 6. The model includes a no-fail zone within which the failure features of the material model are suppressed. This prevents inadvertent edge effects to appear. As can been seen from Figure 7, this zone includes part of the edge of the panel as well as the frame and loadcells.

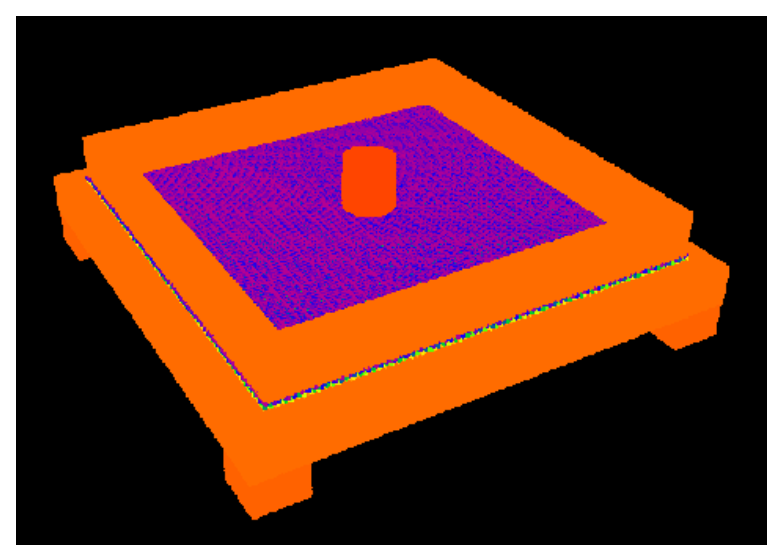

Figure 6: Peridynamic model for ballistic limit test

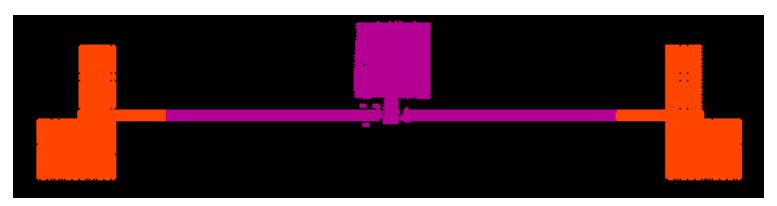

Figure 7: Model section cut showing "no-fail" zone

American Institute of Aeronautics and Astronautics 


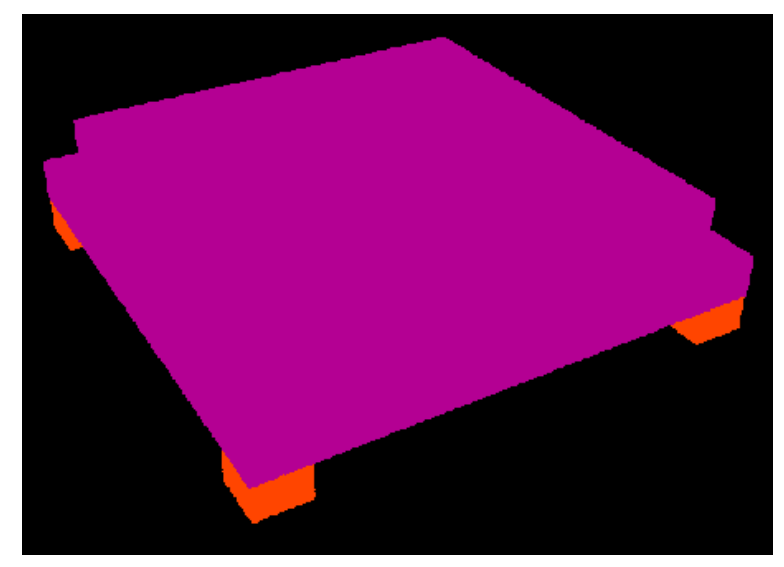

Figure 8: Peridynamic model displacement boundary conditions

An out-of-plane displacement constraint was applied to the loadcells as shown in Figure 8 to represent the stiff test fixture.

\section{Peridynamic Simulation Results}

The out-of-plane displacement results at the last step of the peridynamic simulation can be seen in Figure 9. It is important to note that even though the panel and impactor show large displacements, the end result is a rebound of the impactor, which matches what was observed in the test. As can be seen in Figure 10, at the last step the impactor has a positive velocity, which indicates it is moving away from the panel in a direction opposite to its intial velocity. The test T-B-03 was performed at a higher impact velocity of $\mathrm{v}_{1}=290 \mathrm{ft} / \mathrm{s}$ and the projectile penetrated the panel, continuing to move forward with a residual velocity of $\mathrm{v}_{2}=62 \mathrm{ft} / \mathrm{s}$. Therefore the $\mathrm{V}_{50}$ velocity for this panel-impactor combination is defined as $\mathrm{V}_{50}=\left[\mathrm{v}_{1}{ }^{2}-\mathrm{v}_{2}{ }^{2}\right]^{0.5}=283.3 \mathrm{ft} / \mathrm{s}$.

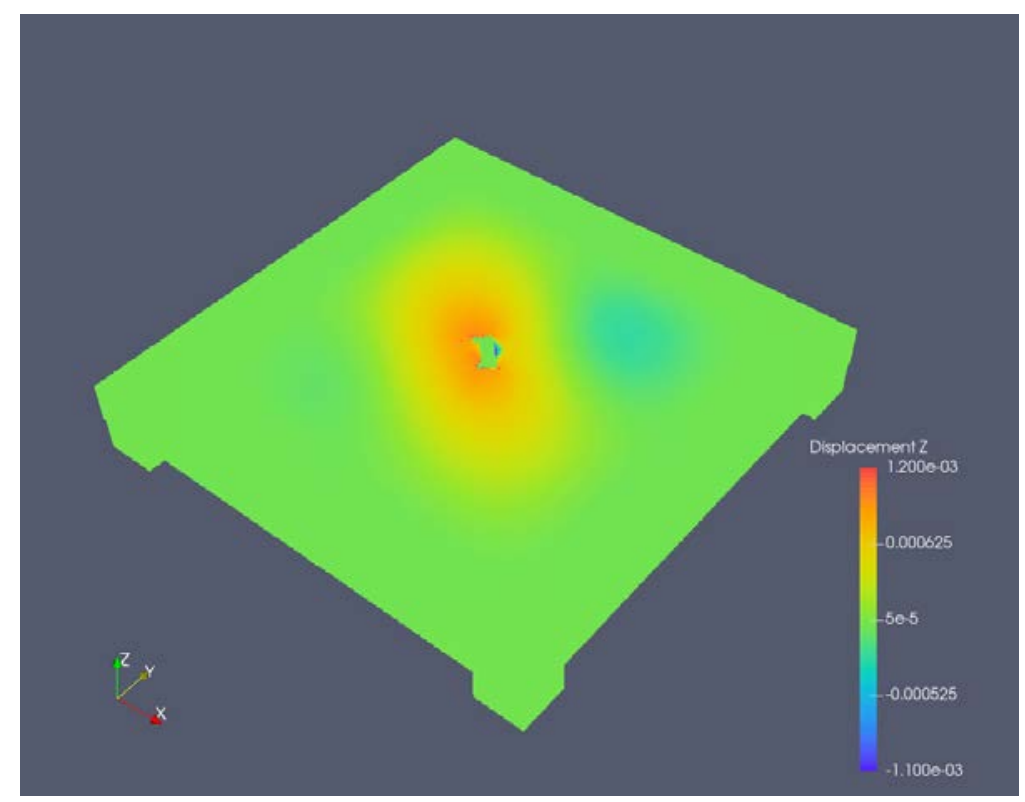

Figure 9: U3 displacement contours after 3ms 


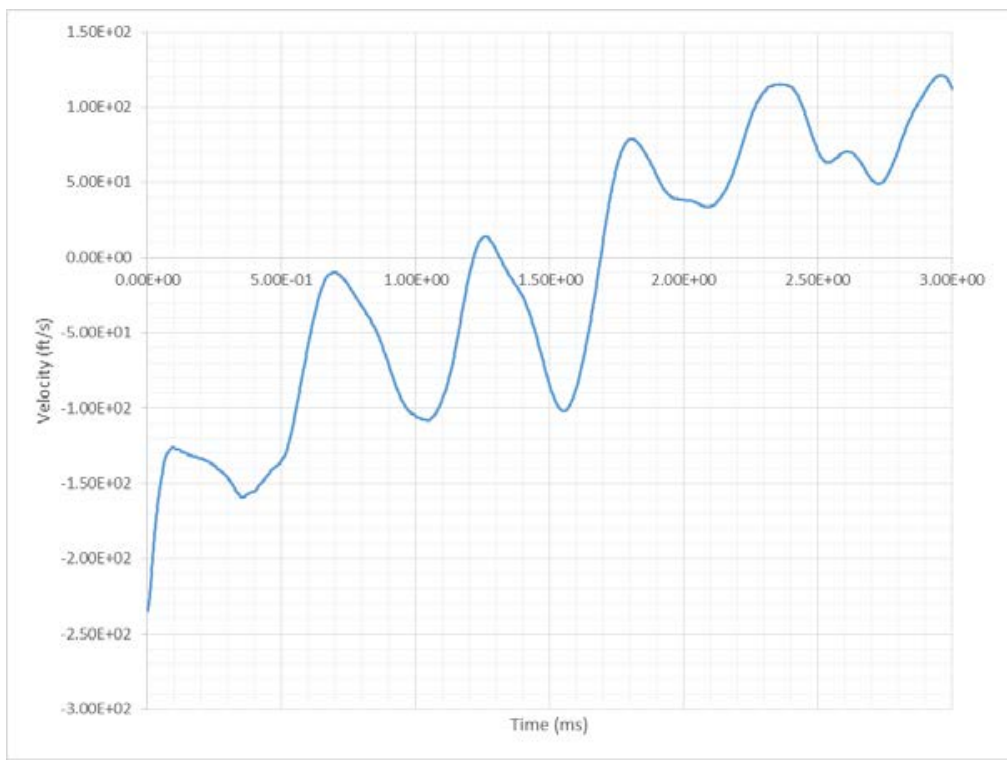

Figure 10: Velocity V3 time history

Figure 11 shows the localized damage to the panel caused by the titanium blade.

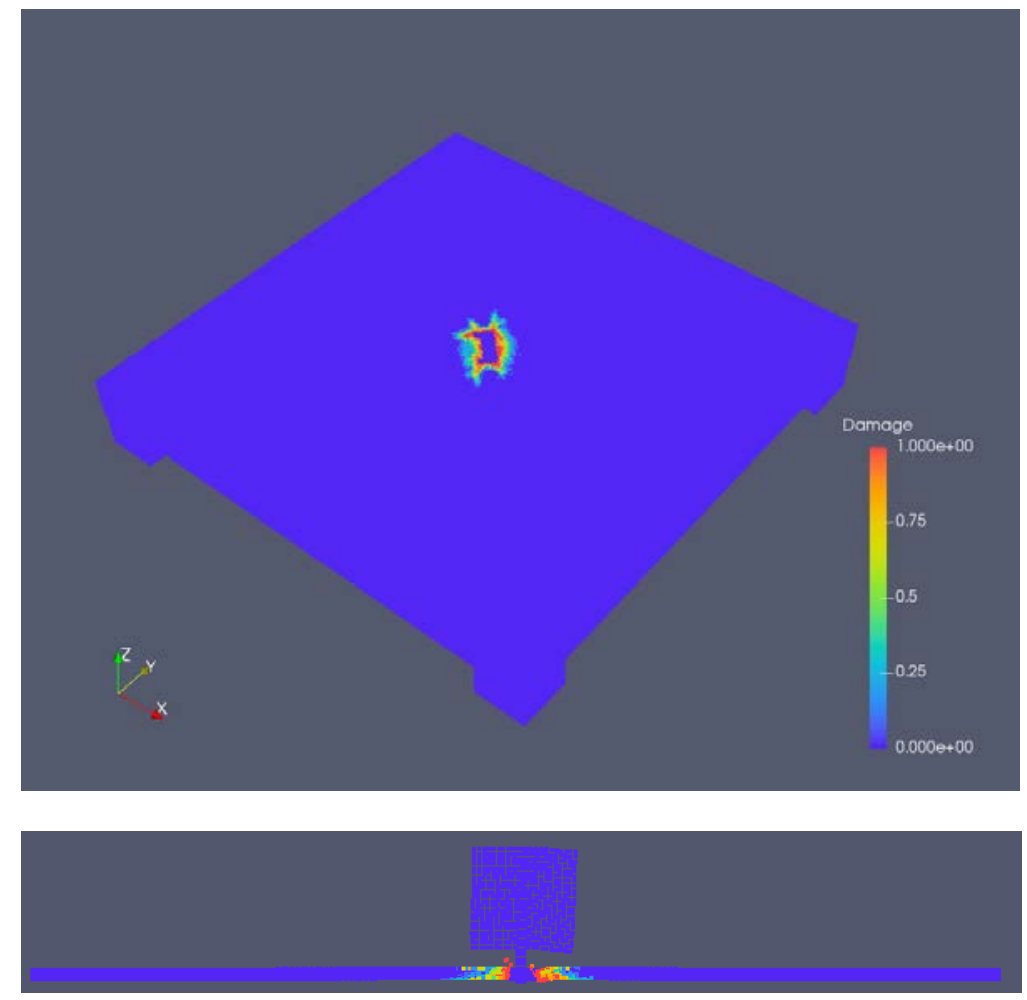

Figure 11: Composite damage contours after 3ms 


\section{E. Test-Analysis Correlation}

Detailed impact test to analysis correlation was performed by comparing the model damage contours against NDE data as well as simulation impact force time history against the collected loadcell data and the panel displacement measured through digital image correlation (DIC) at a point 5.5" off the center of the panel in the horizontal direction.

Figure 12 shows a side by side comparison of the damage contours between the peridynamic model and NDE time of flight data, showing good correlation in the damage pattern. A ply-by-ply study would be necessary to determine the extent of delamination as a function of thickness as represented in the NDE image.
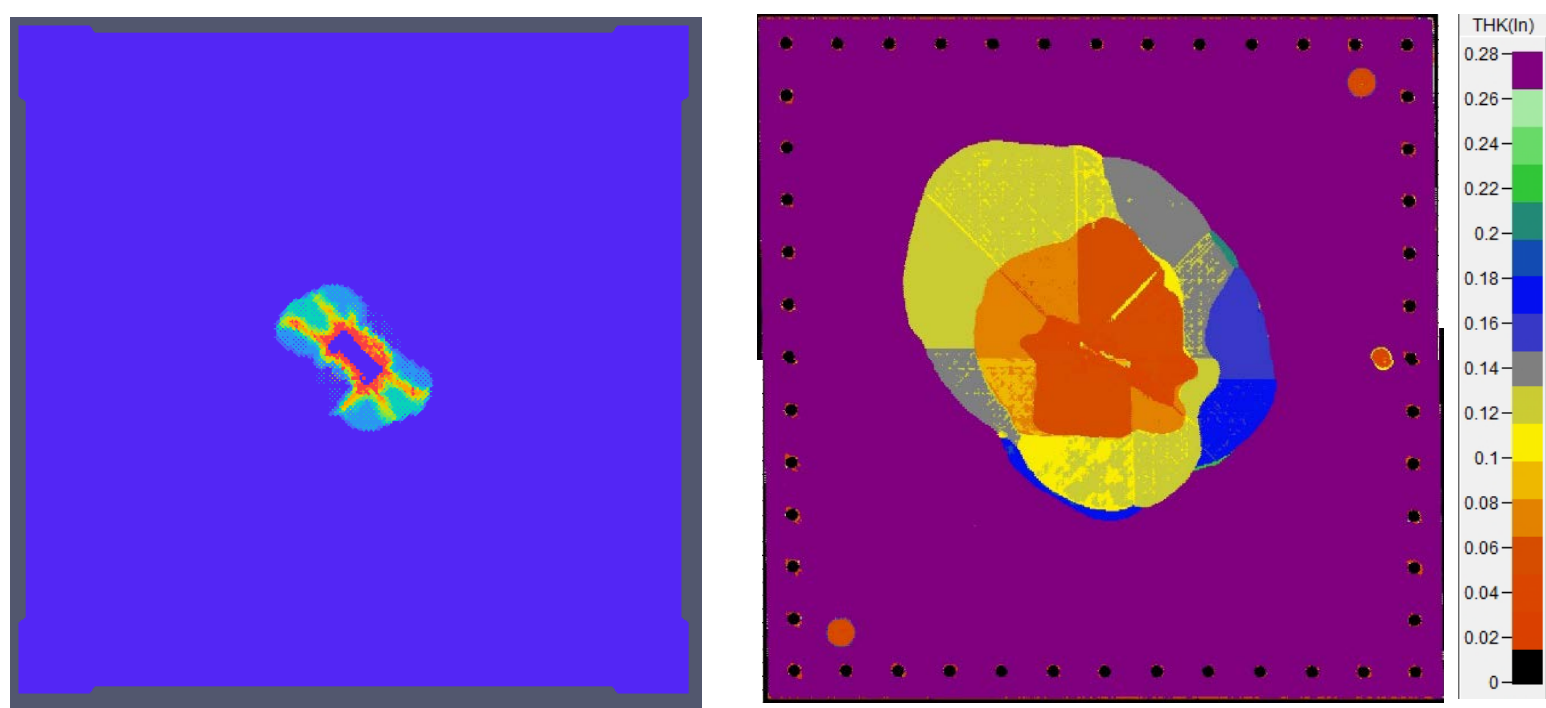

Figure 12: Peridynamic damage plot (left) compared to NDE time-of-flight data (right) for open test case.

The impact force correlation shows good prediction of the dynamic impact wave with a slight underprediction of the total impact force (Figure 13). This could be attributed to the idelization of the test fixture in the model, given that some of the elements have not been modeled (i.e. bolts).

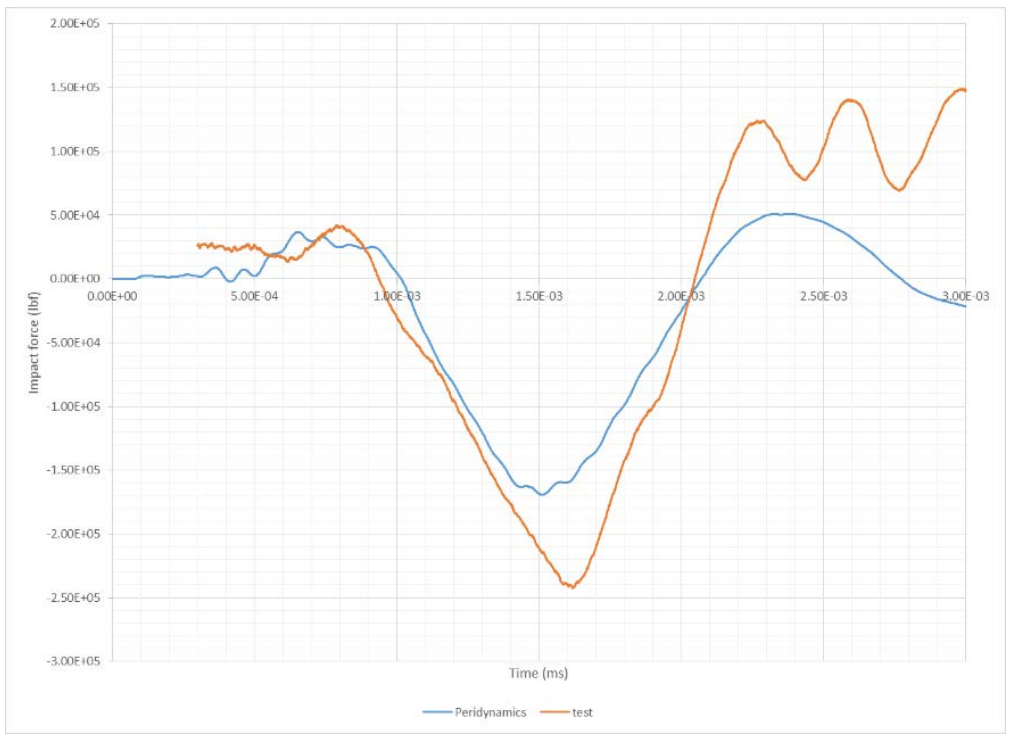

Figure 13: Impact load test-analysis correlation

American Institute of Aeronautics and Astronautics 
Furthermore the displacement test-analysis correlation shows very good prediction of the panel's initial displacement after impact, with a visible difference in the subsequent wave likely due to differences in damping between the simulation and the real structure (Figure 14). Overall the results are considered to be a good measure of the peridynamic model's ability to predict the dynamnic response of impact loading for this material system. This model idealization is used in the blind ballistic limit predictions shown in Section III.

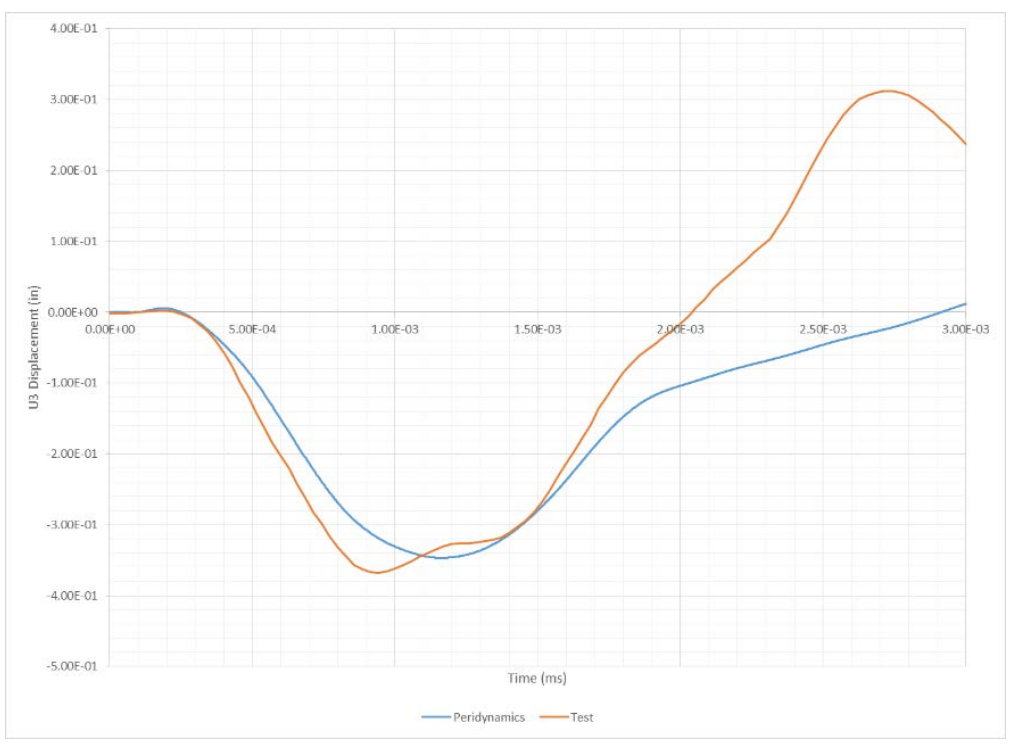

Figure 14: Out-of plane displacement test-analysis correlation 


\section{Blind Predictions for Ballistic Limit $\left(\mathbf{V}_{50}\right)$}

Once the peridynamic model described in Section II showed an acceptable behavior, a series of pre-test predictions were performed to determine the ballistic limit $\left(\mathrm{V}_{50}\right)$ velocity of six different composite panels. The only available information regarding these tests were the material, stacking sequence (both traditional and non-traditional laminates) and the type of impactor used. The reported $\mathrm{V}_{50}$ was determined by iteratively.

Figure 15 shows the out-of plane displacement contours for the sharp (left hand side) and blunt (right hand side) impact prior to penetration on a 56-ply traditional laminate panel. Notice the localized deformation caused by the sharp titanium impactor which has an smaller impact area compared to the blunt flexane impactor.
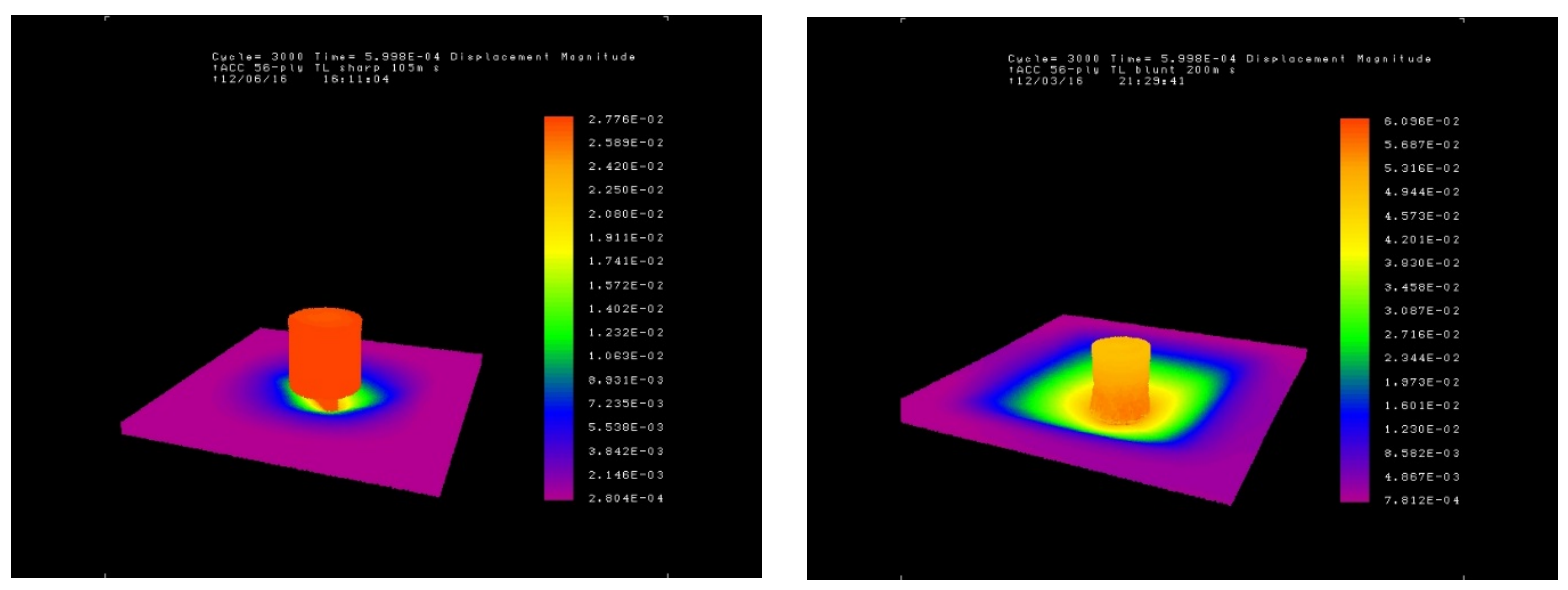

Figure 15: Panel out-of plane deformation due to sharp (left) and blunt impactor (right).

Figure 16 shows a comparison between blunt and sharp pre-test impact results for both traditional and nontraditional laminates with NASA ACC HEDI test data for $\mathrm{V}_{50}$. These blind predictions showed excellent correlation to the test data.

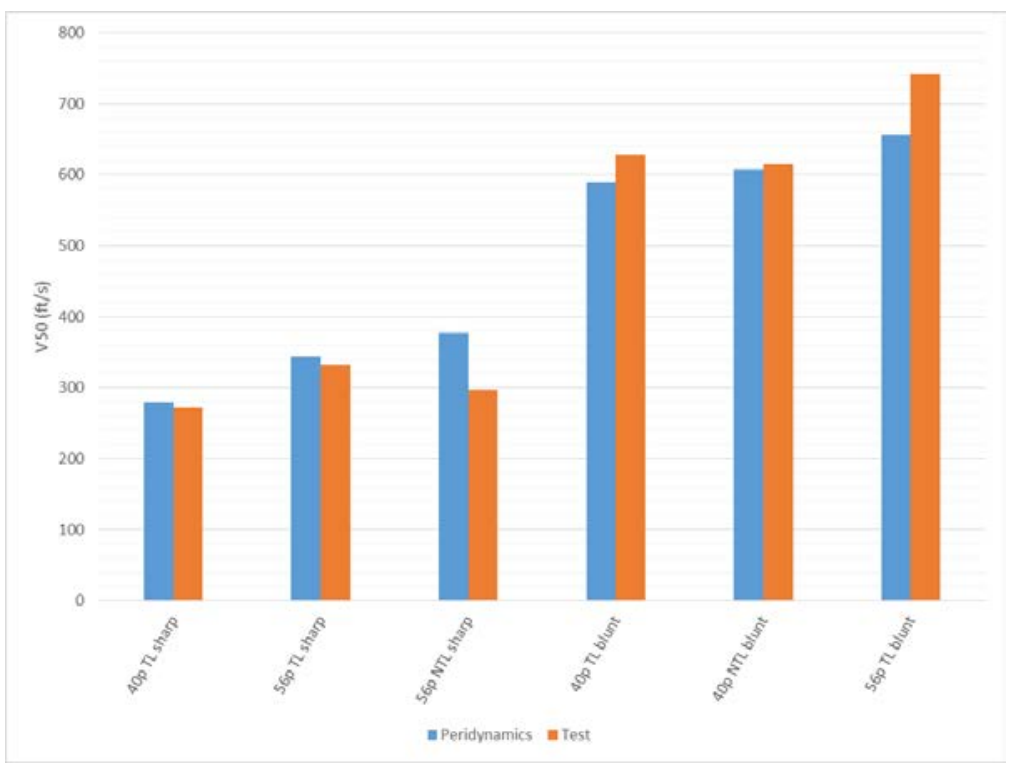

Figure 16: Traditional and non-traitional laminate $V_{50}$ pre-test predictions. 
Table 5: Summary of $V_{50}$ test results

\begin{tabular}{|c|c|}
\hline Test & $\mathbf{V}_{\mathbf{5 0}}$ (ft/s) \\
\hline 40p TL sharp & 272 \\
\hline 56p TL sharp & 331 \\
\hline 56p NTL sharp & 297 \\
\hline 40p TL blunt & 628 \\
\hline 40p NTL blunt & 615 \\
\hline 56p TL blunt & 742 \\
\hline
\end{tabular}

\section{Summary}

In this paper we presented peridynamic simulation for high velocity impact events with the goal of determining the ballistic limit, or $\mathrm{V}_{50}$ velocity. We have shown that peridynamics has the ability to predict damage patterns, impact force and deflections during a high energy dynamic impact event on composite panels of different layups using two different types of impactors. The peridynamic model was first correlated to an open test case and then a series of blind predictions were performed which in turn were validated against test data when it became available. The blind predictions were excellent, further increasing our confidence in the model. Future work needs to address these inputs if the response of more complex configured structures in HEDI Phase 2 efforts.

\section{Acknowledgements}

The material in this paper is based upon work supported by NASA under Award No. NNL09AA00A. Any opinions, findings, and conclusions or recommendations expressed in this material are those of the author(s) and do not necessarily reflect the views of the National Aeronautics and Space Administration. 


\section{References}

1. NASA ACC High Energy Dynamic Impact Methodology and Outcomes, by Kenneth J. Hunziker, Jenna K. Pang, Matthew E. Melis, Michael Pereira and Mostafa Rassaian

2. Comparison of Test Methods to Determine Failure Parameters for MAT162 Calibration, by Matthew Molitor, Brian Justusson, Jenna K. Pang, and Mostafa Rassaian

3. Determination of Ballistic Limit for IM7/8552 Using MAT261, by Alan Byar, Jeff Iqbal, Jenna Pang, and Mostafa Rassaian

4. Dynamic Impact Testing and Model Development in Support of NASA's Advanced Composites Program, by Matthew E. Melis, Michael Pereira, Robert Goldberg, and Mostafa Rassaian

5. Reformulation of elasticity theory for discontinuities and longrange forces by S. A. Silling. J. Mech. Phys. Solids 48 (2000)1, pp. 175 - 209

6. Peridynamics States and Constitutive Modeling, by Silling, S, Epton, E, Weckner, O, Xu, J, Askari, A. Journal of Elasticity 88 (2) pp. 151-184, 2007

7. Modeling shock waves and impact phenomena with Eulerian peridynamics by SA Silling, LP Parks, JR Kamm, O Weckner, M Rassaian. International Journal of Impact Engineering (2017) 